\title{
Fatigue strength of a radical nitrided Ni-base super alloy
}

\author{
K. Morino ${ }^{1}$, N. Kawagoishi ${ }^{2}$, K. Yamane $^{3} \&$ K. Fukada ${ }^{3}$ \\ ${ }^{1}$ Tokuyama College of Technology, Shunan, Japan \\ ${ }^{2}$ Faculty of Engineering, Kagoshima University, Kagoshima, Japan \\ ${ }^{3}$ Kohan Kogyo Co. Ltd., Kudamatsu, Japan
}

\begin{abstract}
Radical nitriding was applied to Ni-base super alloy, Alloy 718, which is difficult to nitride and the fatigue strength of the alloy was also investigated in comparison with the aged alloy under push-pull loading at room temperature and $500^{\circ} \mathrm{C}$. By radical nitriding, compound layer of about $5 \mu \mathrm{m}$ was formed and specimen surface was hardened over HV1300. Consequently, fatigue strength was increased in wide life region, especially beyond $10^{6}$ cycles at room temperature. This was mainly caused by the suppression of crack initiation due to formation of hard compound layer. There was no or little difference in fatigue strengths between specimen removed nitrided layer by electro-polishing and aged specimen. That is, radical nitriding method is effective to improve the fatigue strength at room temperature without the damage of matrix.
\end{abstract}

Keywords: fatigue, alloy 718 steel, nitriding, aging, elevated temperature, compound layer, crack initiation.

\section{Introduction}

Ni-base super alloys are used under severe conditions like a high temperature or severe corrosive environment because of their superior properties on corrosion, creep, static strength at high temperature and so on [1-3]. Therefore these alloys have been used as a major material of gas turbine, jet engine and so on. However the alloy is inferior to wear resistance. To improve the wear performance and fatigue properties, surface modifications are applied. Radical nitriding is one of superior surface treatment methods, because the method can apply to nitriding of metals like an austenitic stainless steel with passive film, control the formation of 
compounds, keep surface smoother and especially minimize the damage of matrix because of its low treatment temperature. However, it is difficult to nitride Ni-base super alloy, except for high temperature treatment like an ion nitriding.

In the present study, radical nitriding was applied to Ni-base super alloy, Alloy 718, and the fatigue strength of the alloy was also investigated in comparison with the aged alloy at room temperature and $500^{\circ} \mathrm{C}$ under push-pull loading.

\section{Materials and experimental procedure}

The material used was a Ni-base super alloy, Alloy 718, with a chemical composition (in wt. $\%$ ) of $0.02 \mathrm{C}, 0.11 \mathrm{Si}, 0.12 \mathrm{Mn}, 0.009 \mathrm{P}, 0.001 \mathrm{~S}, 18.67 \mathrm{Cr}$, 3.09Mo, 0.09Co, 0.01Cu, 0.66Al, 0.90Ti, 18.67Fe, 0.004B, 5.12 Nb and $\mathrm{Ta}$, and balance Ni. The material was solution treated at $982^{\circ} \mathrm{C}$ for $1 \mathrm{hr}$ and then water quenched. After solution treatment, the material was aged at $720^{\circ} \mathrm{C}$ for $8 \mathrm{hr}$, then furnace cooled to $621^{\circ} \mathrm{C}$ and aged at $621^{\circ} \mathrm{C}$ for $8 \mathrm{hr}$ followed by air-cooling. The mean grain size of the material was about $18 \mu \mathrm{m}$. Mechanical properties of aged alloy at room temperature and $500^{\circ} \mathrm{C}$ were $0.2 \%$ proof stresses of $1147 \mathrm{MPa}$ and $1050 \mathrm{MPa}$, tensile strengths of $1372 \mathrm{MPa}$ and $1235 \mathrm{MPa}$ and reduction of areas of $38.1 \%$ and $40.9 \%$, respectively.

Figure 1 shows shape and dimensions of specimen. All of the specimens were electro-polished by $\sim 40 \mu \mathrm{m}$ in diameter from the surface after machining and emery paper grinding in order to remove the worked layer and to make the observation of surface damage easier. Moreover, parts of aged specimen were nitrided under the conditions shown in fig. 2.

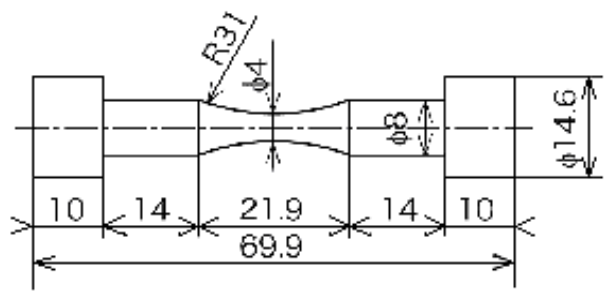

Figure 1: $\quad$ Shape and dimensions of specimen.

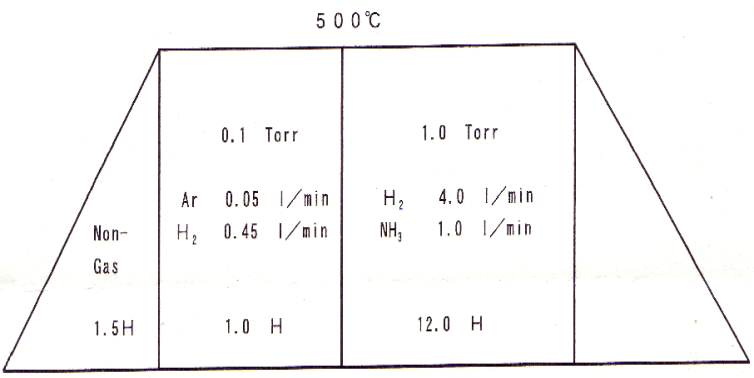

Figure 2: Nitriding conditions. 


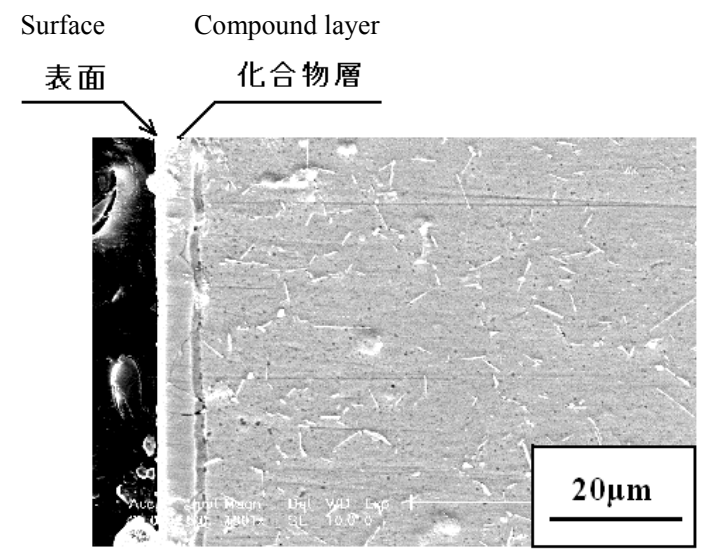

Figure 3: $\quad$ Microstructure of nitrided alloy.

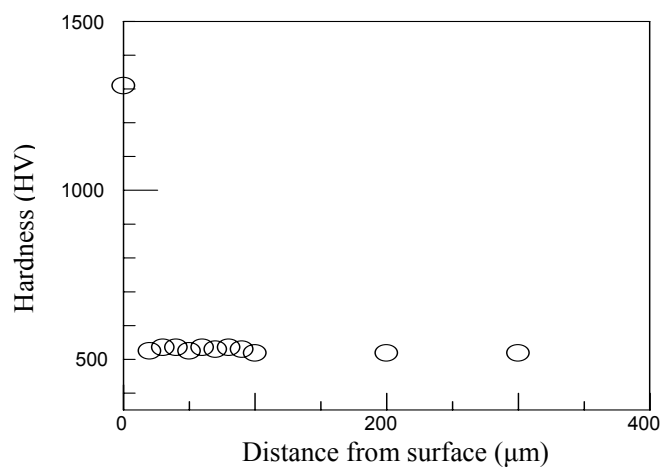

Figure 4: Hardness distribution.

Figure 3 shows microstructure of nitrided alloy. Compound layer with about $5 \mu \mathrm{m}$ in thickness is confirmed.

Figure 4 shows hardness distribution of cross section of specimen. Hardness of compound layer is about HV1300.

The measurement of surface damage and fracture surface were examined by using an optical microscope through plastic replica or a scanning electron microscope (SEM) directly. Fatigue tests were carried out using a push-pull fatigue testing machine at room temperature and $500^{\circ} \mathrm{C}$ in ambient atmosphere under stress ratio of -1 . The loading frequency was $5 \mathrm{~Hz}$.

\section{Results and discussion}

\subsection{Fatigue strength of nitrided alloy at room temperature}

Figure 5 shows S-N curves of nitrided and aged specimens at room temperature. Fatigue strength was increased by nitriding, especially at low stress levels. All of 


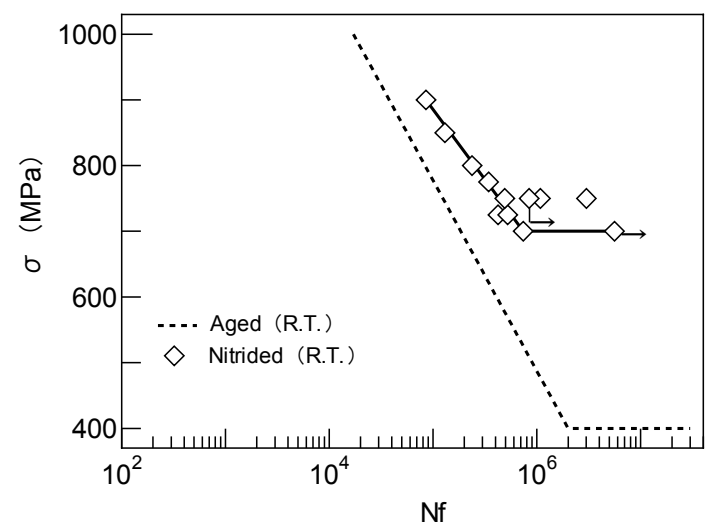

Figure 5: $\quad$ S-N curves of nitrided and aged specimens at room temperature.

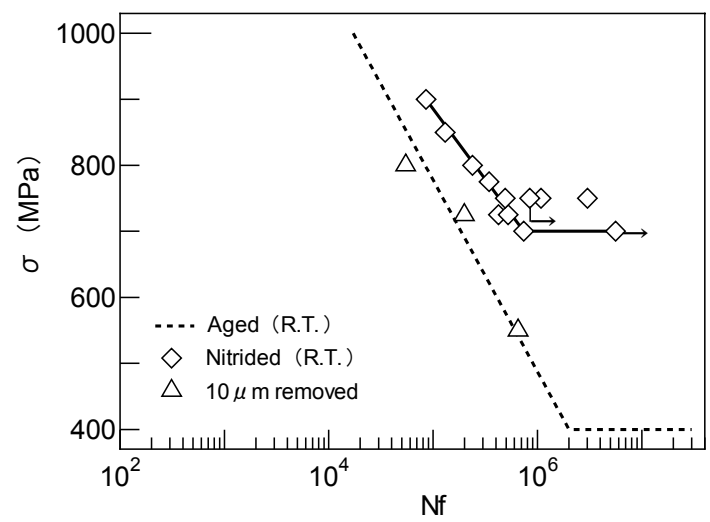

Figure 6: Fatigue strength of specimen removed nitrided layer.

fractures occurred from specimen surface, though subsurface fracture occurred in many surface treated metals [4-6].

Figure 6 shows fatigue strength of specimen removed nitrided layer by electro-polishing from the surface of nitrided specimen. The fatigue strength of nitrided layer removed specimen is the same as that of aged specimen. This means that radical nitriding did not give any damage. This may be attributed to its low nitriding temperature.

Figure 7 shows crack morphologies observed at specimen surfaces in both alloys. The crack of aged alloy propagates in zigzag manner, while the crack morphology of nitrided alloy is straight, meaning that a brittle crack propagated.

Figure 8 shows fracture surfaces of both alloys. As seen from the surface observation of a crack, there is thin and flat layer corresponding thickness to compound layer near the specimen surface which means that a crack propagates in brittle manner in nitrided alloy, while fracture surface of aged alloy is ductile. 


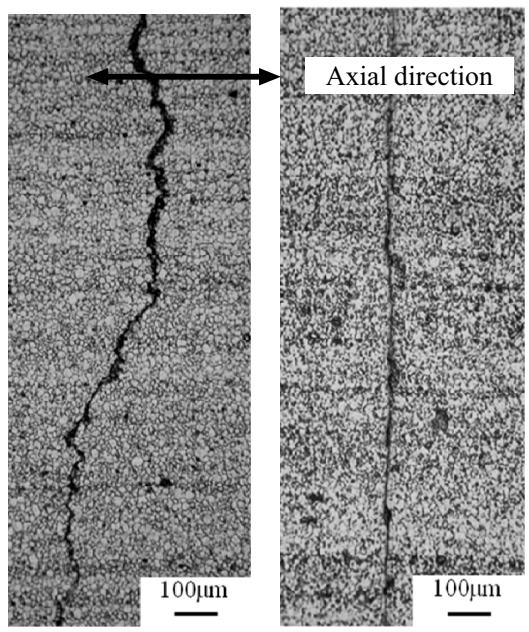
(a) Aged alloy
(b) Nitrided alloy
$\left(\mathrm{Nf}=6.82 \times 10^{4}\right)$
$\left(\mathrm{Nf}=1.84 \times 10^{5}\right)$

Figure 7: Crack morphology at room temperature.

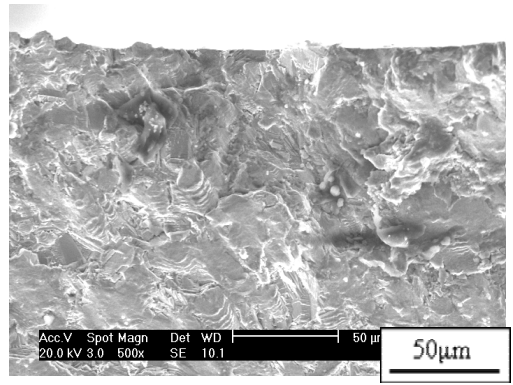

(a) Aged alloy

$\left(\sigma\right.$ a $\left.=500 \mathrm{MPa}, \mathrm{Nf}=9.23 \times 10^{5}\right)$

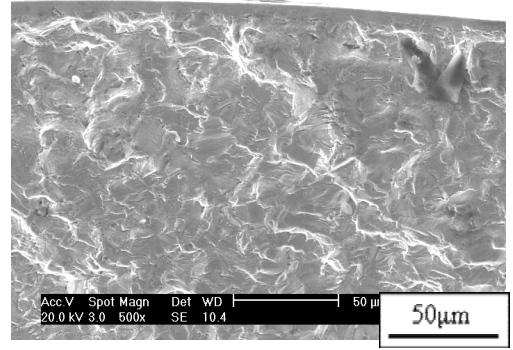

(b) Nitrided alloy

$$
\text { ( } \sigma \mathrm{a}=750 \mathrm{MPa}, \mathrm{Nf}=3.0 \times 10^{6} \text { ) }
$$

Figure 8: $\quad$ Fracture surfaces at room temperature.

From the results mentioned above, it can be understood that the increase in fatigue strength by nitriding was caused by suppression of a crack initiation and the effect on the propagation of a crack was small. Moreover, small increase in fatigue strength at high stress level can be explained from the propagation of a brittle crack yielded by the large difference in Young's modulus between compound layer and matrix under large deformation. 


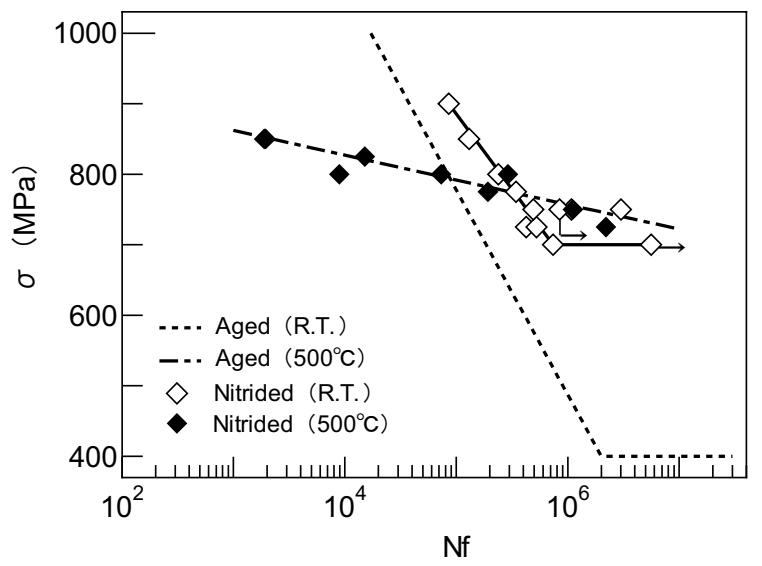

Figure 9: $\quad$ S-N curves of nitrided and aged specimens at 500.

\subsection{Fatigue strength of nitrided alloy at 500}

Figure 9 shows S-N curves of nitrided and aged specimens at $500^{\circ} \mathrm{C}$. In the figure, the results at room temperature are also drawn by lines only. Fatigue strength was not increased by nitriding, the increase in fatigue strength is almost the same in comparison with the results at room temperature. However, fatigue strength at $500^{\circ} \mathrm{C}$ is higher than that at room temperature under low stress levels, and it is converse under high stress levels.

Figure 10 shows crack morphologies observed at specimen surfaces of nitrided alloys at high stress. All of fracture at high stress occurred from specimen surface. There are many brittle cracks on the surface. These brittle cracks did not observe at specimen surface of aged specimen.

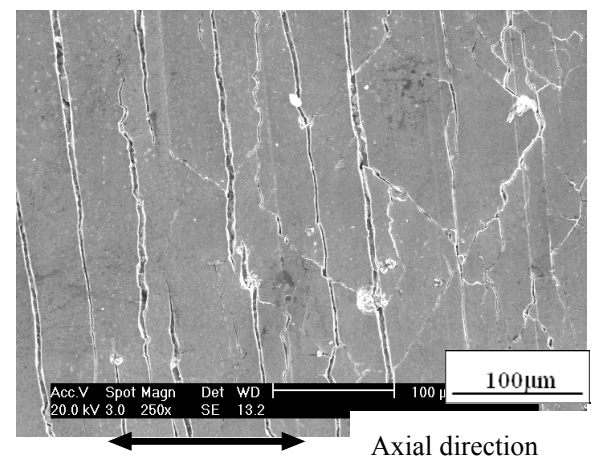

Figure 10: Crack morphology of nitrided alloy at $500^{\circ} \mathrm{C}$.

Figure 11 shows fracture surfaces of both alloys. As understood from the surface observation of a crack, the feature of fracture surfaces of both alloys is similar to the results at room temperature. However, fracture surface near the 


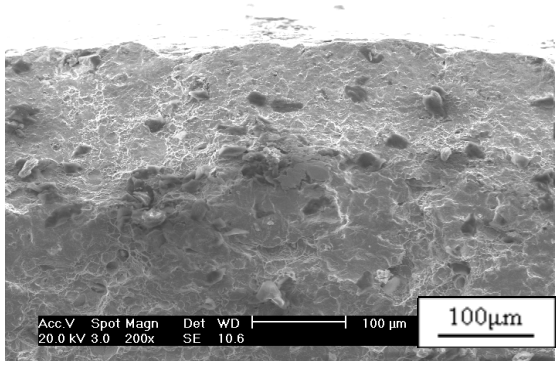

(a) Aged alloy

$\left(\sigma \mathrm{a}=700 \mathrm{MPa}, \mathrm{Nf}=3.27 \times 10^{6}\right)$

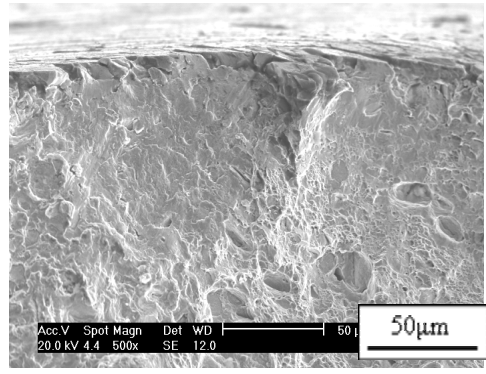

(b) Nitrided alloy

$\left(\sigma \mathrm{a}=750 \mathrm{MPa}, \mathrm{Nf}=1.11 \times 10^{6}\right)$

Figure 11: $\quad$ Fracture surfaces at $500^{\circ} \mathrm{C}$.

surface of nitrided alloy is more brittle at $500^{\circ} \mathrm{C}$ than at room temperature. This tendency was marked at high stress levels. The difference in brittlement between room temperature and $500^{\circ} \mathrm{C}$ is a reason for the difference in nitriding effect on fatigue strength at both temperatures. That is, the difference in Young's modulus between compound layer and matrix is large at high temperature, because the effect of temperature on hardness is smaller in compound layer than in matrix.

\section{Conclusions}

Radical nitriding was applied to Ni-base super alloy, Alloy 718, and the fatigue strength of the alloy was also investigated in comparison with the aged material under push-pull loading at room temperature and $500^{\circ} \mathrm{C}$. By radical nitriding, compound layer of about $5 \mu \mathrm{m}$ was formed and specimen surface was hardened over HV1300. Fatigue strength was increased in wide life region, especially beyond $10^{6}$ cycles at room temperature. This was mainly caused by the suppression of crack initiation due to formation of hard compound layer. There was no or little difference in fatigue strengths between specimen removed nitrided layer by electro-polishing and aged specimen. That is, this method is effective to improve the fatigue strength without the damage of matrix.

\section{References}

[1] Hwang, S.K., Lee, H.N. \& Yoon, H.H., Metallurgical Transaction A, 20A, pp.2793-2801, 1975.

[2] Grabowski, L. \& Yates, J.R., Int. J. Fatigue, 14, pp. 227-232, 1992.

[3] Anderson, H., Persson, C. \& Hansson, T., Int. J. Fatigue, 23, pp.817- 827, 2001.

[4] Kawagoishi, N., Morino, K., Fukada, K., Chen, Q. \&Kondo, E., Surface Treatment V, WIT Press, pp.209-217, 2001. 
182 Surface Effects and Contact Mechanics IX

[5] Shiozawa, K., Tao, L. \& Ishihara, S., J. Soc. Mater. Sci., Japan, 48, pp.1095-1100, 1999.

[6] Nakajima, M., Sakai, T. \& Shimazu, T., Trans. Japan Soc. Mech. Eng. A, 65, pp. 2504-2510, 1999. 